\title{
Predictors of Postoperative Seizure Outcome in Low Grade Glioma: From Volumetric Analysis to Molecular Stratification
}

\author{
Tamara Ius $^{1, * \mathbb{D}}$, Giada Pauletto ${ }^{2}$, Barbara Tomasino ${ }^{3}{ }^{\mathbb{D}}$, Marta Maieron $^{4}{ }^{(\mathbb{D}}$, Riccardo Budai $^{2}$, \\ Miriam Isola $^{5}$, Daniela Cesselli ${ }^{6}{ }^{\infty}$, Christian Lettieri $^{2}$ and Miran Skrap ${ }^{1}$ \\ 1 Neurosurgery Unit, Department of Neuroscience, Santa Maria della Misericordia University Hospital, \\ 33100 Udine, Italy; skrap@asuiud.sanita.fvg.it \\ 2 Neurology Unit, Department of Neuroscience, Santa Maria della Misericordia University Hospital, \\ 33100 Udine, Italy; giada.pauletto@asuiud.sanita.fvg.it (G.P.); riccardo.budai@asuiud.sanita.fvg.it (R.B.); \\ christian.lettieri@asuiud.sanita.fvg.it (C.L.) \\ 3 Scientific Institute, IRCCS E. Medea, San Vito al Tagliamento, 33078 Pordenone, Italy; btomasino.ud@lnf.it \\ 4 Medical Physics, Santa Maria della Misericordia University Hospital, 33100 Udine, Italy; \\ marta.maieron@asuiud.sanita.fvg.it \\ 5 Department of Medicine, Santa Maria della Misericordia University Hospital, 33100 Udine, Italy; \\ miriam.isola@uniud.it \\ 6 Institute of Pathology, Santa Maria della Misericordia University Hospital, 33100 Udine Post, Italy; \\ daniela.cesselli@uniud.it \\ * Correspondence: tamara.ius@asuiud.sanita.fvg.it or tamara.ius@gmail.com; \\ Tel.: +39-347-0178730/+39-0432-554493
}

Received: 24 December 2019; Accepted: 6 February 2020; Published: 8 February 2020

\begin{abstract}
The importance of the extent of resection (EOR) has been widely demonstrated as the main predictor for survival, nevertheless its effect on tumor related epilepsy is less investigated. A total of 155 patients were enrolled after a first-line surgery for supratentorial Diffuse Low Grade Gliomas (DLGGs). Postoperative seizure outcome was analyzed stratifying the results by tumor volumetric data and molecular markers according to 2016 WHO classification. Receiver operating characteristic (ROC) curves were computed to asses EOR, residual tumor volume, and $\triangle \mathrm{T} 2 \mathrm{~T} 1 \mathrm{MRI}$ index (expressing the tumor growing pattern) corresponding to optimal seizure outcome. A total of $70.97 \%$ of patients were seizure-free 18 months after surgery. Better seizure outcome was observed in IDH1/2 mutated and 1p/19q codeleted subgroup. At multivariate analysis, age $(p=0.014)$, EOR $(p=0.030), \Delta \mathrm{T} 2 \mathrm{~T} 1 \mathrm{MRI}$ index $(p=0.016)$ resulted as independent predictors of postoperative seizure control. Optimal parameters to improve postoperative seizure outcome were EOR $\geq 85 \%, \Delta \mathrm{T} 2 \mathrm{~T} 1 \mathrm{MRI}$ index $\leq 18 \mathrm{~cm}^{3}$, residual tumor volume $\leq 15 \mathrm{~cm}^{3}$. This study confirms the role of EOR and tumor growing pattern on postoperative seizure outcome independently from the molecular class. Higher $\Delta \mathrm{T} 2 \mathrm{~T} 1 \mathrm{MRI}$ index, representing the infiltrative component of the tumor, is associated with worse seizure outcome and strengthens the evidence of common pathogenic mechanisms underlying tumor growth and postoperative seizure outcome.
\end{abstract}

Keywords: low grade glioma; seizure outcome; molecular markers; extent of resection; tumor growth pattern; ROC curves

\section{Introduction}

Seizure is the most common onset symptom in patients with supratentorial diffuse low grade gliomas (DLGG), with a seizure frequency ranging from $60 \%$ to $90 \%[1,2]$. Tumor-related epilepsy tends 
to manifest with focal and focal-to-bilateral tonic-clonic seizures, and more than $50 \%$ of cases show pharmaco-resistance, which contributes negatively on quality of life [3-5]. Recent studies have pointed out that epileptogenesis and tumor growth in DLGG may share common pathogenic mechanisms that can influence each other, thus representing two aspects of the same disease [6]. In this context, several genetic alterations have been identified as risk factors of glioma-related epilepsy. Mutations of the gene encoding the isocitrate-dehydrogenase1 (IDH1) and 2 (IDH2) can be found in about 70\%-80\% of DLGG [7]. These mutations have been associated with metabolic changes that are potentially epileptogenic, in accordance with the capability of IDH-mutated glioma cells to penetrate and surround the neurons in the gray matter [8,9].

Seizure outcome represents an important challenge in the daily management of DLGG patients. In particular, decision-making still varies across surgical centers given the lack of well-established and universally recognized predictors of seizure outcomes.

In the last decades, numerous studies, based on the objective evaluation of the extent of resection (EOR) has been published, demonstrating that an extensive surgery leads to increased overall patient survival and decreased malignant progression [10-14].

Although EOR has also been shown to be one of the main strongest significant predictor markers for seizure outcome [7,15-18], its predictive role has not been completely clarified in complex predictor models for epileptic outcome stratification combining molecular and tumor volumetric data.

We assessed the capability of the main clinical, molecular, and radiological data used in DLGG, including the tumor growing pattern and EOR, to predict postoperative seizure outcome, with the aim to provide useful tools for the early identification of postoperative seizure persistence and for the refinement of medical treatment tailoring in subjects with refractory epilepsy.

\section{Results}

\subsection{Study Population and Postoperative Seizure Outcome}

Demographic, clinical, histological, molecular, and radiological data of the 155 DLGG patients included in the study are summarized in Tables 1 and 2. Seizure features are plotted in Figure 1 according to the preoperative Anti-Epileptic Drugs (AEDs). Overall, the median duration between seizure onset and surgery was 6 months (range 4-20 months). The preoperative MRI evidenced in all cases the absence of enhancement on T1-weighted post contrast MRI sequences. The median preoperative tumor volume, computed on T2-weighted MR images, was $48 \mathrm{~cm}^{3}$ (range $6-144 \mathrm{~cm}^{3}$ ). The median preoperative $\Delta \mathrm{T} 2 \mathrm{~T} 1 \mathrm{MRI}$ value was $12 \mathrm{~cm}^{3}$ (range $0-55 \mathrm{~cm}^{3}$ ). The median EOR was $88 \%$ (range 38\%-100\%) and the median postoperative residual tumor was $10 \mathrm{~cm}^{3}$ (range 0-44). According to the 2016 WHO classification of the brain tumors, based on morphology and molecular alterations, 44 oligodendroglioma, IDH-mutant, and 1p/19q codeleted, 93 diffuse astrocytoma, IDH-mutant, and 18 diffuse astrocytoma, IDH-wild type, were identified. 
Table 1. Baseline characteristics of the study population. Characteristics of the study population are described using means \pm s.d. (standard deviation) or median and range for continuous variables, number of cases with relative percentages reported in parentheses for categorical variables. Abbreviations: $\triangle \mathrm{T} 2 \mathrm{~T} 1 \mathrm{MRI}$ index, volumetric difference between preoperative tumor volumes on T2 and T1 weighted MRI images; EOR, extent of surgical resection.

\begin{tabular}{|c|c|}
\hline Parameters & $\begin{array}{c}\text { Value } \\
(\mathrm{N} \text { and } \%, \text { Mean } \pm \text { s.d. or Median and Range) }\end{array}$ \\
\hline No. of patients & 155 \\
\hline \multicolumn{2}{|l|}{ Sex } \\
\hline Female & $59(38.06 \%)$ \\
\hline Male & $96(61.94 \%)$ \\
\hline Age (years) & 37 18-73) \\
\hline \multicolumn{2}{|l|}{ Tumor side } \\
\hline Left & $88(56.77 \%)$ \\
\hline Right & $67(43.23 \%)$ \\
\hline \multicolumn{2}{|l|}{ Tumor site } \\
\hline Frontal & $50(32.26 \%)$ \\
\hline Parietal & $13(8.39 \%)$ \\
\hline Temporal & $24(15.48 \%)$ \\
\hline Insular & $65(41.94 \%)$ \\
\hline Occipital & $3(1.93 \%)$ \\
\hline $\begin{array}{l}\text { Preoperative tumor volume computed on } \\
\text { T2-weighted MRI images, } \mathrm{cm}^{3}\end{array}$ & $48(6-144)$ \\
\hline Preoperative $\Delta \mathrm{T} 2 \mathrm{~T} 1 \mathrm{MRI}$ index, $\mathrm{cm}^{3}$ & $12(0-55)$ \\
\hline \multicolumn{2}{|l|}{ Preoperative $\Delta$ VT2T1 MRI index } \\
\hline$<18 \mathrm{~cm}^{3}$ & $88(56.67 \%)$ \\
\hline$\geq 18 \mathrm{~cm}^{3}$ & $67(43.23 \%)$ \\
\hline $\mathrm{EOR} \%$ & $88(38-100)$ \\
\hline \multicolumn{2}{|l|}{$\mathrm{EOR} \%$} \\
\hline 100 & $30(19.36 \%)$ \\
\hline $99-90$ & $43(27.74 \%)$ \\
\hline $70-89$ & $45(29.03 \%)$ \\
\hline$\leq 69$ & $37(23.87 \%)$ \\
\hline $\begin{array}{l}\text { Postoperative residual tumor volume computed on } \\
\text { T2-weighted MRI images, } \mathrm{cm}^{3}\end{array}$ & $10(0-44)$ \\
\hline \multicolumn{2}{|l|}{ Molecular class } \\
\hline $\begin{array}{l}\text { Oligodendroglioma IDH1/2 mutated 1p-19q } \\
\text { codeleted }\end{array}$ & $44(28.39 \%)$ \\
\hline Astrocytoma IDH $1 / 2$ mutated $1 \mathrm{p}-19 \mathrm{q}$ non codeleted & $93(60.00 \%)$ \\
\hline Astrocytoma IDH $1 / 2$ wild type & $18(11.61 \%)$ \\
\hline MGMT & 136 vs. 19 \\
\hline $\begin{array}{l}\text { Methylation status } \\
\text { yes vs. no }\end{array}$ & $(87.74 \%$ vs. $12.26 \%)$ \\
\hline \multicolumn{2}{|l|}{ Intraoperative protocol } \\
\hline Awake surgery & $113(72.90 \%)$ \\
\hline General anesthesia & $42(27.10 \%)$ \\
\hline Time between seizure onset and surgery & 6 months (range $4-20$ months) \\
\hline
\end{tabular}


Table 2. Seizure characteristics. Abbreviations: AEDs, anti-epileptic drugs.

\begin{tabular}{|c|c|}
\hline Parameter & N (\%) \\
\hline \multicolumn{2}{|l|}{ Onset Seizure Features } \\
\hline Focal & $52(33.55 \%)$ \\
\hline Motor & 18 \\
\hline Non motor sensory & 17 \\
\hline Non motor emotional & 2 \\
\hline Non motor cognitive & 11 \\
\hline Non motor autonomic & 4 \\
\hline Generalized & $103(66.45 \%)$ \\
\hline Motor & 76 \\
\hline Focal to bilateral & 14 \\
\hline Absence & 9 \\
\hline Non motor cognitive & 2 \\
\hline Non motor emotional & 1 \\
\hline Non motor sensory & 1 \\
\hline \multicolumn{2}{|l|}{ Seizure Frequency } \\
\hline Monthly & $92(59.35 \%)$ \\
\hline Weekly & $52(33.55 \%)$ \\
\hline Daily & $11(7.10 \%)$ \\
\hline \multicolumn{2}{|l|}{ Duration } \\
\hline$<1$ year & $133(85.81 \%)$ \\
\hline$>1$ year & $22(14.19 \%)$ \\
\hline \multicolumn{2}{|l|}{ Preoperative AEDs } \\
\hline Levetiracetam & $96(61.94 \%)$ \\
\hline Polytherapy & $27(17.42 \%)$ \\
\hline Carbamazepine & $22(14.19 \%)$ \\
\hline Phenytoin & $10(6.45 \%)$ \\
\hline \multicolumn{2}{|l|}{ Postoperative Engel Class } \\
\hline IA & $110(70.97 \%)$ \\
\hline IB, IC, ID & $16(10.32 \%)$ \\
\hline II, III & $23(14.84 \%)$ \\
\hline IV & $6(3.87 \%)$ \\
\hline \multicolumn{2}{|l|}{ Postoperative AEDs } \\
\hline Levetiracetam & $105(67.74 \%)$ \\
\hline Polytherapy & $31(20.00 \%)$ \\
\hline Oxcarbamazepina & $6(3.86 \%)$ \\
\hline Carbamazepine & $5(3.23 \%)$ \\
\hline Valproic Acid & $5(3.23 \%)$ \\
\hline Lacosamide & $3(1.94 \%)$ \\
\hline
\end{tabular}


A

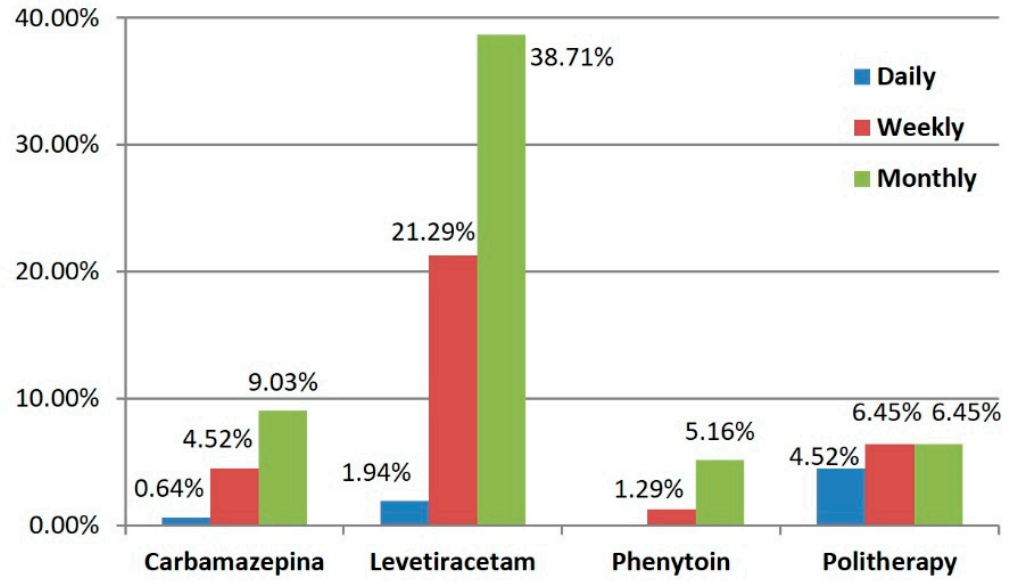

B

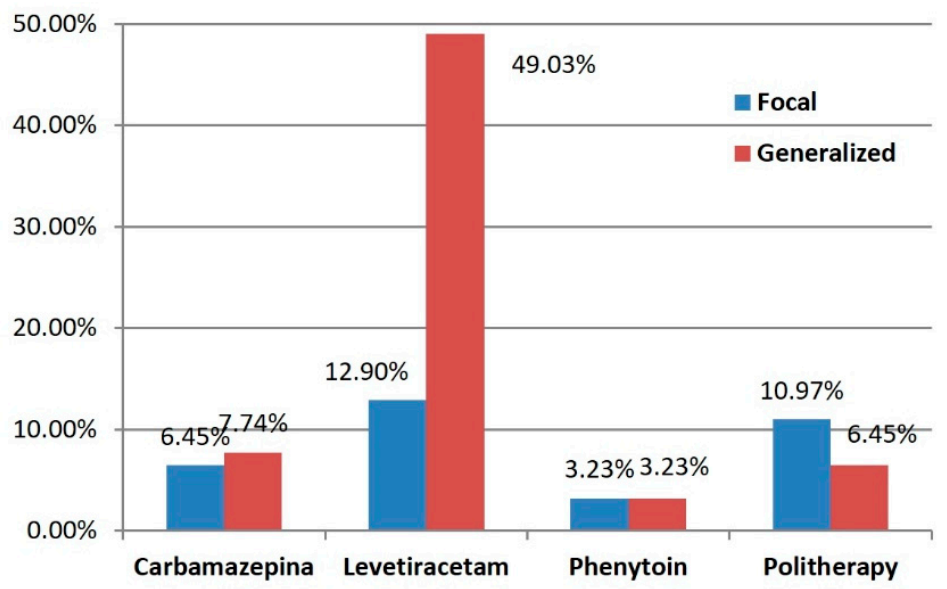

Figure 1. Graph illustrating the preoperative Anti-Epileptic Drugs (AESs) stratified by seizure frequency (A) and by onset seizure type (B).

\subsection{Postoperative Seizure Outcome Analysis}

Postoperative seizure outcome was proportionally similar at the four analyzed time points $(4,8$, 12, and 18-month follow-up). By considering the entire cohort of 155 cases, postoperative seizure control at 18 months was as follows: 110 patients $(70.97 \%)$ were classified as Engel Class IA (completely seizure free), 16 patients (10.32\%) as Engel Class IB-ID, 23 patients (14.84\%) as Engel Class II-III, and six patients (3.87\%) as Engel Class IV. The distribution, according to different postoperative seizure outcome (Engel Class IA vs. IB-IV), of EOR, residual tumor, molecular class, and preoperative $\triangle T 2 T 1$ $M R I$ index, and intraoperative protocol are represented in Figure 2. 
A

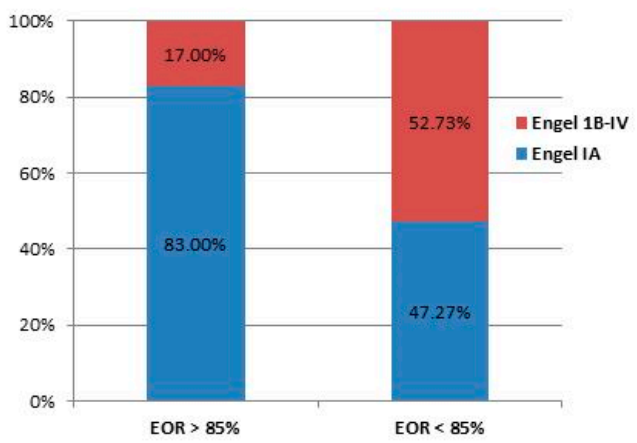

B

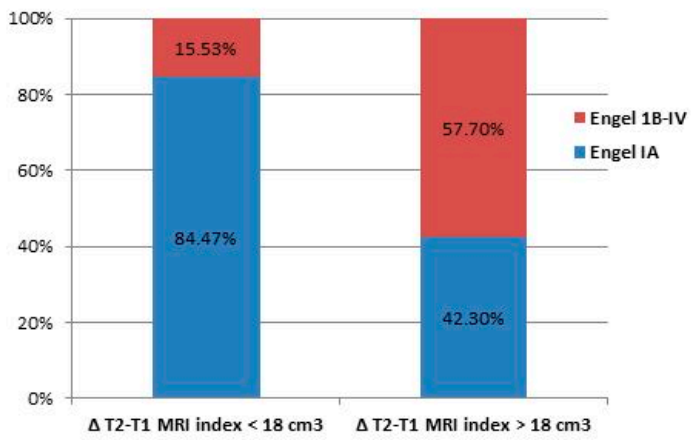

$$
\text { C }
$$

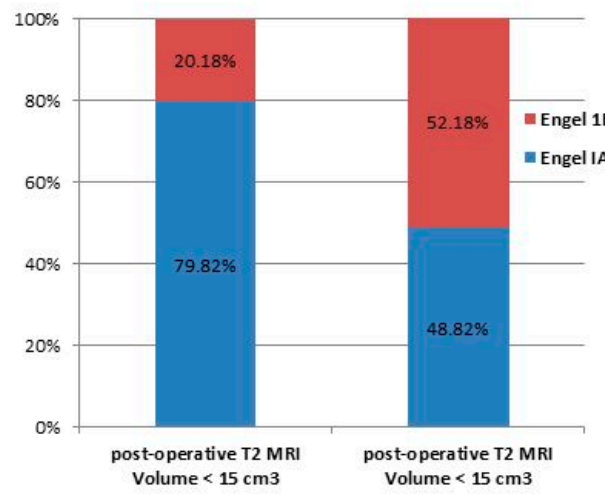

\section{D}

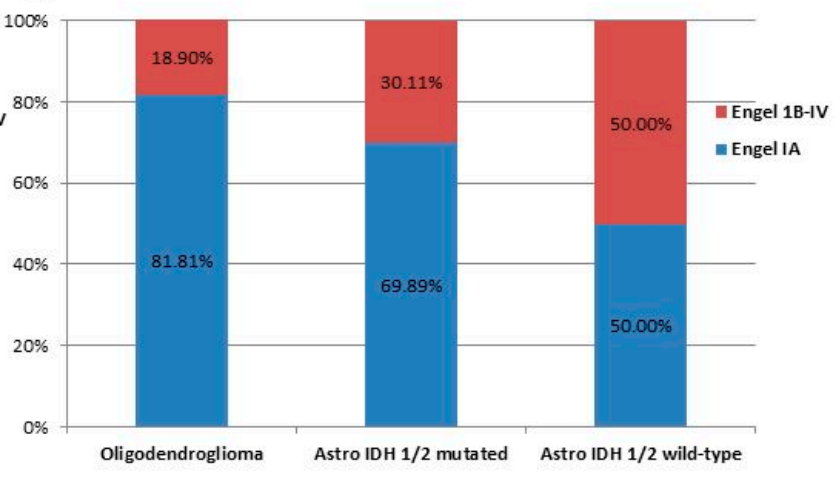

Figure 2. Graph illustrating 18-months postoperative seizure outcome stratified by the significant variables at univariate analysis. Blue bars indicate patients in Engel Class IA; yellow bars indicate those in Engel Class IB or above. Individual bar totals are the total number of patients with postoperative seizures within each category. (A) Distribution of patients stratified by the EOR; (B) Distribution of patients stratified by the preoperative tumor growing pattern expressed by the $\triangle \mathrm{T} 2 \mathrm{~T} 1 \mathrm{MRI}$ index; (C) distribution of patients stratified by the residual tumor computed on T2 weighted images; (D) distribution of patients stratified by the molecular class according to the $2016 \mathrm{WHO}$ classification.

Patients of Engel Class IB-IV required changes in AEDs therapy to optimize seizure control after surgery. As shown by the 18-month postoperative follow-up evaluation, these therapeutic changes, however, failed to produce complete seizure freedom, and no other patients achieved Engel Class IA.

AEDs changes was usually done for patients belonging to Engel Class IA and IB. For all the others, we proceeded with changings and/or optimization of the pharmacological treatments (i.e., add on therapy, a new AED as monotherapy, increased posology). Specifically, further surgery, radiotherapy or chemotherapy were not considered, in patients not seizure free after surgery, based on the fact that all cases showed no signs of tumor progression within the follow-up considered.

At univariate analysis the following parameters were associated with postoperative seizure outcome: frequency of preoperative seizures; seizure-onset features; preoperative $\Delta \mathrm{T} 2 \mathrm{~T} 1 \mathrm{MRI}$ index; molecular class; EOR; AEDs in mono- or poly-therapy; and postoperative residual tumor computed on T2-weighted images.

In a multivariate analysis model which considered all these variables, only age $(p=0.014), \Delta \mathrm{T} 2 \mathrm{~T} 1$ MRI index $(p=0.016)$, and EOR $(p=0.030)$ were shown to be independent predictors of outcome (Table 3). 
Table 3. Predictors of 18 months postoperative seizure control (Engel IA) on univariate and multivariate analyses. Boldfacing values represent statistically significant results $(p<0.05)$.

\begin{tabular}{|c|c|c|c|c|c|c|}
\hline \multirow{2}{*}{ Variable } & \multicolumn{3}{|c|}{ Univariate Analysis } & \multicolumn{3}{|c|}{ Multivariate Analysis } \\
\hline & Odds Ratio & $95 \%$ CI & $p$-Value & Odds Ratio & $95 \% \mathrm{CI}$ & $p$-Value \\
\hline Age (yrs) & 1.042 & $1.010-1.074$ & 0.009 & 1.056 & $1.010-1.103$ & 0.014 \\
\hline \multicolumn{7}{|l|}{ Sex } \\
\hline Male & 1 & & & & & \\
\hline Female & 1.456 & $0.718-2.950$ & 0.297 & & & \\
\hline \multicolumn{7}{|l|}{ Tumor side } \\
\hline Left & 1 & & & & & \\
\hline Right & 1.044 & $0.290-3.758$ & 0.947 & & & \\
\hline \multicolumn{7}{|l|}{ Tumor Site } \\
\hline Pre-central & 1 & & & & & \\
\hline Retro-central & 0.755 & $0.207-2.752$ & 0.671 & & & \\
\hline Temporal & 0.497 & $0.159-1.552$ & 0.229 & & & \\
\hline Insular & 0.723 & $0.328-1.591$ & 0.421 & & & \\
\hline \multicolumn{7}{|l|}{$\begin{array}{l}\text { Onset seizure } \\
\text { features }\end{array}$} \\
\hline Generalized & 1 & & & & & \\
\hline Focal & 1.057 & $0.324-2.267$ & 0.013 & & & \\
\hline \multicolumn{7}{|l|}{ Seizure frequency } \\
\hline Monthly & 1 & & & & & \\
\hline Weekly & 1.457 & $0.690-3.076$ & 0.323 & & & \\
\hline Daily & 2.500 & $0.697-8.966$ & 0.160 & & & \\
\hline \multicolumn{7}{|l|}{ Duration } \\
\hline$<1 \mathrm{yr}$ & 1 & & & & & \\
\hline$>1 \mathrm{yr}$ & 0.857 & $0.324-2.267$ & 0.756 & & & \\
\hline $\begin{array}{l}\text { Preoperative } \\
\text { tumor volume }\end{array}$ & & & & & & \\
\hline $\begin{array}{l}\text { computed on } \\
\text { T2-weighted } \\
\text { images, } \mathrm{cm}^{3}\end{array}$ & 1.116 & $1.069-1.185$ & $<0.0001$ & & & \\
\hline $\begin{array}{l}\Delta \mathrm{T} 2 \mathrm{~T} 1 \mathrm{MRI} \text { index } \\
\text { Molecular Class }\end{array}$ & 1.156 & $1.066-1.195$ & $<0.0001$ & 1.077 & $1.102-1.134$ & 0.016 \\
\hline Astrocytoma & & & & & & \\
\hline $\begin{array}{l}\text { IDH } 1 / 2 \text { mutated } \\
\text { 1p-19q non } \\
\text { codeleted }\end{array}$ & 1 & & & & & \\
\hline $\begin{array}{l}\text { Astrocytoma } \\
\text { IDH1/2 wild type }\end{array}$ & 0.430 & $0.154-1.200$ & 0.107 & & & \\
\hline \multicolumn{7}{|l|}{ Oligodendroglioma } \\
\hline IDH1/2 mutated & 0.222 & $0.669-0.747$ & 0.014 & & & \\
\hline \multicolumn{7}{|l|}{$\begin{array}{l}\text { 1p-19q codeleted } \\
\text { MGMT }\end{array}$} \\
\hline $\begin{array}{l}\text { Methylation } \\
\text { yes vs. no } \\
\% \text { EOR }\end{array}$ & 2.382 & $0.658-8.619$ & 0.186 & & & \\
\hline $\begin{array}{l}\text { Continuous } \\
\text { variable }\end{array}$ & $0-929$ & $0.903-0.955$ & $<0.0001$ & 0.957 & $0.920-0.995$ & 0.030 \\
\hline $\begin{array}{l}\text { Postoperative } \\
\text { residual tumor }\end{array}$ & & & & & & \\
\hline $\begin{array}{l}\text { volume computed } \\
\text { on T2 weighted } \\
\text { MRI images, } \mathrm{cm}^{3}\end{array}$ & 1.057 & $0.324-2.267$ & 0.001 & & & \\
\hline
\end{tabular}

\subsection{ROC Analysis}

In order to determine statistical clinical useful postoperative seizure outcome cutoff predictive values for EOR, preoperative $\triangle \mathrm{T} 2 \mathrm{~T} 1 \mathrm{MRI}$ index and residual tumor, a receiver operating characteristic (ROC) curve was computed based on Engel class, using a binary outcome (Engel Class IA versus IB-IV) (Figure 3). 

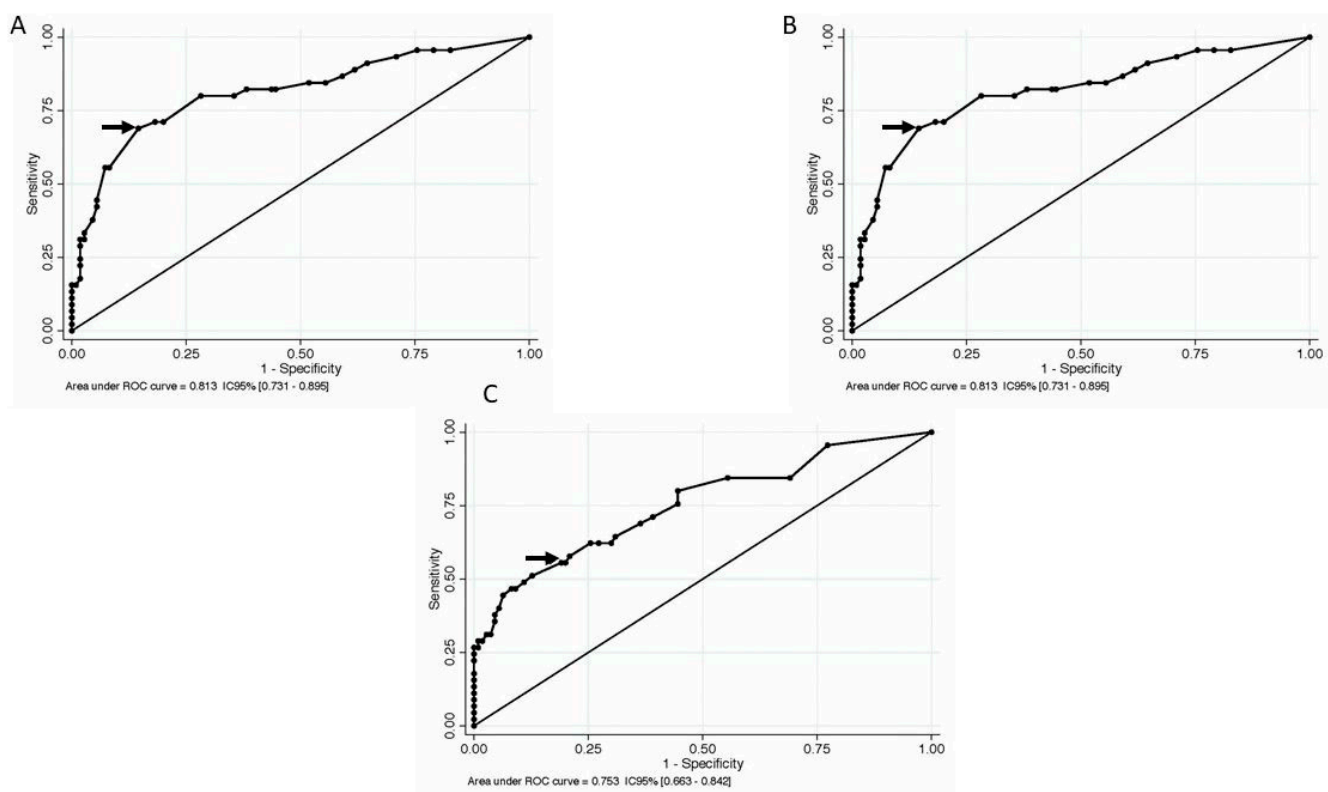

Figure 3. A receiver operating characteristic (ROC) curve for EOR, preoperative $\triangle T 2 T 1 \mathrm{MRI}$ index, and postoperative residua tumor on $\mathrm{T} 2$-weighted images, to predict seizures relapse after surgery. The optimal diagnostic point is the one with maximal sensitivity and specificity. It is the point closest to the top left corner of the graph, indicated by the arrow. (A) The optimal threshold corresponded to an EOR of $85 \%$, which was the point with the highest sensitivity $(0.764)$ and specificity $(0.644)$, with a resulting area under the curve of 0.783 (CI 95\% 0.700-0.865) and a predictive accuracy of $72.90 \%$; (B) for the preoperative $\triangle \mathrm{T} 2 \mathrm{~T} 1 \mathrm{MRI}$ index, the threshold of $18 \mathrm{~cm}^{3}$ corresponded to the point with the highest sensitivity (0.689) and specificity (0.855), with a resulting area under the curve of 0.813 (CI 95\% $0.731-0.895)$ and a predictive accuracy of $82.65 \%$; (C) regarding the residual tumor, the optimal threshold corresponded to $15 \mathrm{~cm}^{3}$, which was the point with the highest sensitivity (0.556) and specificity (0.809), with a resulting area under the curve of 0.753 (CI 95\% $0.663-0.842)$ and a predictive accuracy of $73.55 \%$.

The optimal threshold corresponded to an EOR of $85 \%$, which was the point with the highest sensitivity (0.764) and specificity (0.644), with a resulting area under the curve of 0.783 (CI $95 \%$ $0.700-0.865$ ) and a predictive accuracy of $72.90 \%$.

Regarding the residual tumor, the optimal threshold corresponded to $15 \mathrm{~cm}^{3}$, which was the point with the highest sensitivity (0.556) and specificity (0.809), with a resulting area under the curve of 0.753 (CI 95\% 0.663-0.842) and a predictive accuracy of 73.55\%.

For the preoperative $\triangle \mathrm{T} 2 \mathrm{~T} 1 \mathrm{MRI}$ index, the threshold of $18 \mathrm{~cm}^{3}$ corresponded to the point with the highest sensitivity (0.689) and specificity (0.855), with a resulting area under the curve of 0.813 (CI 95\% 0.731-0.895) and a predictive accuracy of $82.65 \%$.

Based on the preoperative $\triangle \mathrm{T} 2 \mathrm{~T} 1 \mathrm{MRI}$ index an example of proliferative and diffusive DLGG are shown in Figures 4 and 5. 


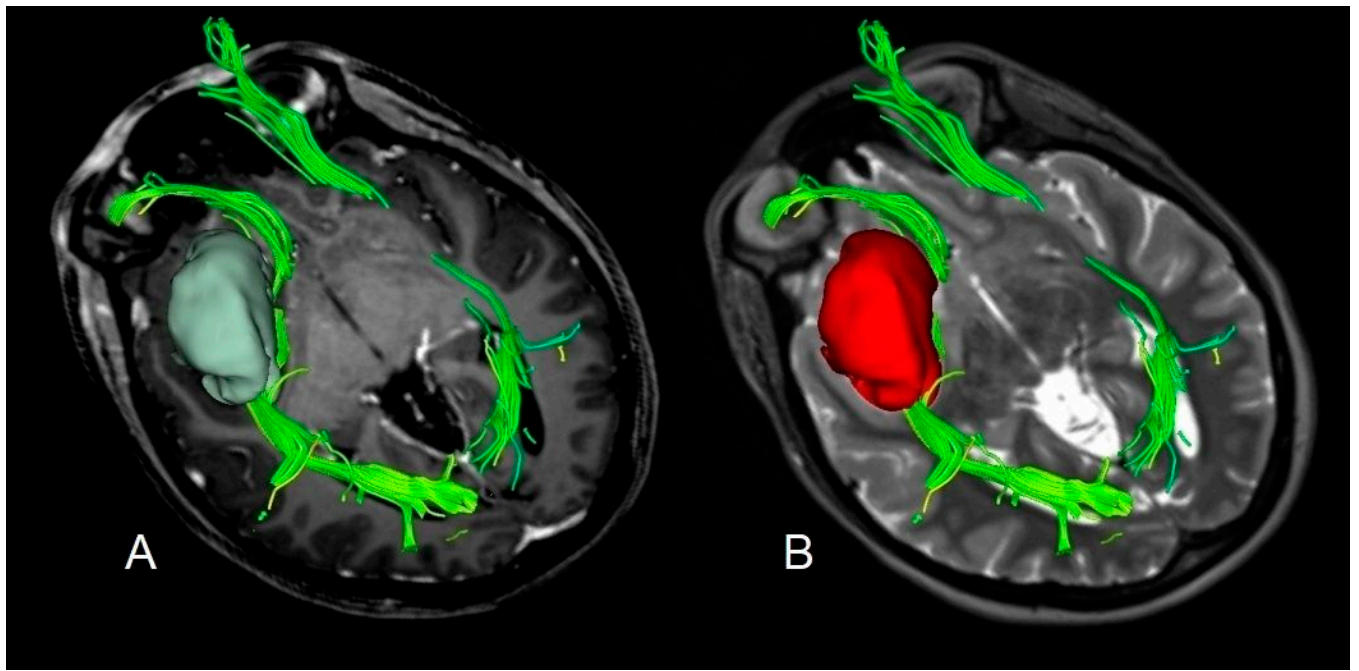

Figure 4. A case of insular diffuse low grade gliomas (DLGG) with a regular shape, determining similar tumor volume in both post-contrast T1-weighted MRI and T2-weighted MRI sequences and displacing the Fronto-Occipital Longitudinal Fasciculus. The preoperative tumor volume computed on post-contrast T1-weighted magnetic resonance imaging (MRI) was $32 \mathrm{~cm}^{3}$ (axial slices A). The preoperative tumor volume computed on T2-weighted MRI was $34 \mathrm{~cm}^{3}$ (axial slices B). The preoperative $\triangle \mathrm{T} 2 \mathrm{~T} 1 \mathrm{MRI}$ index was $2 \mathrm{~cm}^{3}$, showing the prevalence of the proliferative tumor growing pattern. The patient was in Engel Class IA 18 months after surgery.

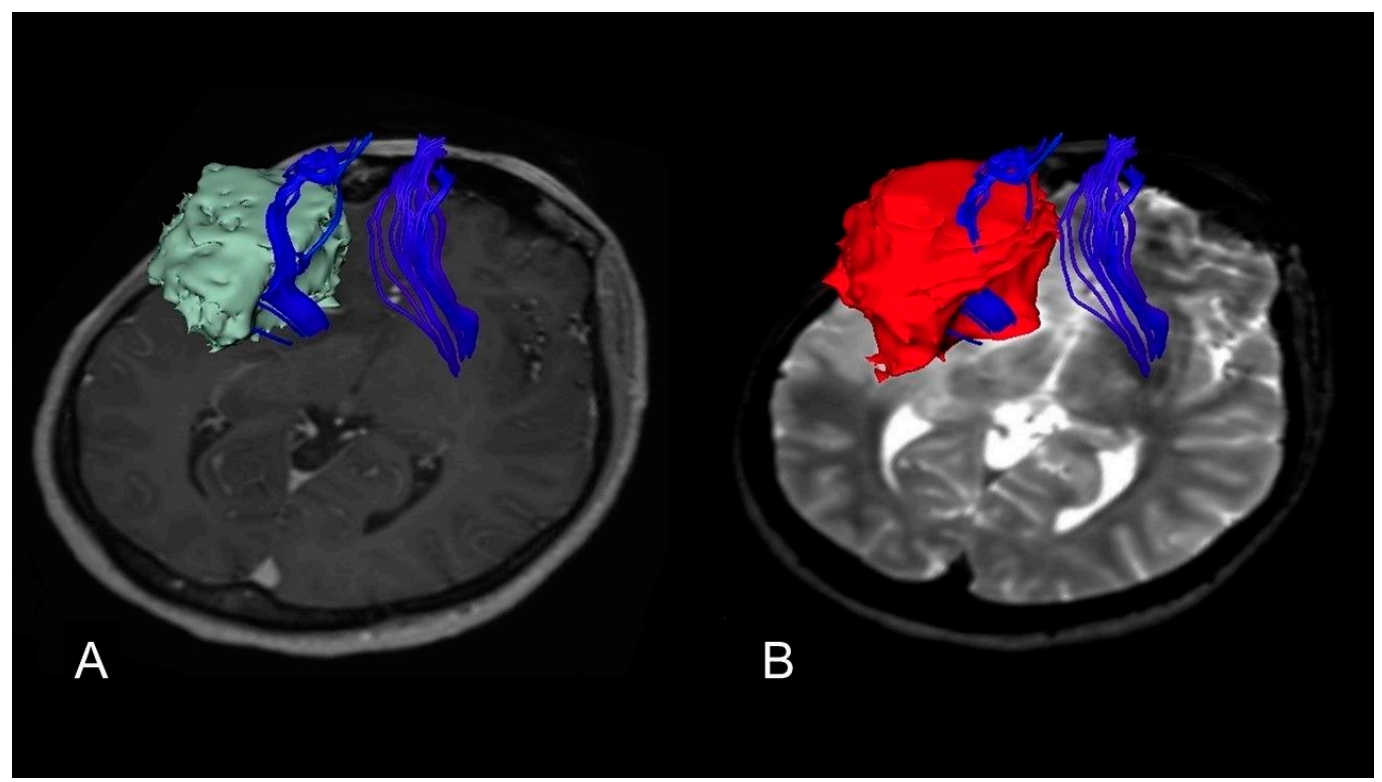

Figure 5. A case of insular DLGG infiltrating the Cortico-Spinal tract. The preoperative tumor volume computed on post-contrast T1-weighted magnetic resonance imaging (MRI) was $58 \mathrm{~cm}^{3}$ (axial slices (A)). The preoperative tumor volume computed on T2-weighted MRI was $83 \mathrm{~cm}^{3}$ (axial slices (B)). The preoperative $\Delta \mathrm{T} 2 \mathrm{~T} 1 \mathrm{MRI}$ index was $25 \mathrm{~cm}^{3}$. The prevalence of the diffusive and infiltrative growth generates the tumor diffusion along the white matter, resulting in a complex shape with digitations more visible on T2-weighted images. The patient was in Engel Class IB 18 months after surgery.

\section{Discussion}

In this retrospective study, which included 155 adult patients DLGG with preoperative drug-resistant tumor related epilepsy, postoperative seizure outcome was analyzed stratifying the results by tumor volumetric data and molecular markers. 
This study showed the following:

(1) $70.97 \%$ of epileptic DLGG patients were in Engel Class IA 18 months after surgery;

(2) Improved postoperative seizure outcome can be expected for EOR $\geq 85 \%$, residual tumor $\leq$ $15 \mathrm{~cm}^{3}$, and preoperative $\Delta \mathrm{T} 2 \mathrm{~T} 1 \mathrm{MRI}$ index $\leq 18 \mathrm{~cm}^{3}$.

(3) Tumor infiltration index, expressed by $\Delta \mathrm{T} 2 \mathrm{~T} 1 \mathrm{MRI}$ index, represents a quantitative evaluation of the diffusive and infiltrative tumor component as predictor of postoperative seizure outcome.

(4) IDH1/2 mutation may represent the prevalent epileptogenic mechanism in presence of higher $\triangle \mathrm{T} 2 \mathrm{~T} 1 \mathrm{MRI}$ index and consequent lower EOR.

\subsection{The Role of EOR}

The treatment paradigm of DLGGs is based on the principle of the onco-functional balance, which implies maximization of EOR with preservation of quality of life.

The role of EOR as the strongest predictors of postoperative seizure long-term outcome (Table 4) has recently been demonstrated in a limited number of retrospective studies [8,15-17,19-23]. Only two investigations examined which value of EOR corresponded to the threshold above which seizure control, defined as Engel Class level, was optimal [16,17].

$\mathrm{Xu}$ et al. showed the existence of an EOR threshold for long-term seizure freedom corresponding to an EOR $>80 \%$ [17].

In a subsequent larger multi-center investigation, methodologically well-designed, Still et al. demonstrated that postoperative seizure control was more likely when EOR was $\geq 91 \%$ and/or when residual tumor volume was $\leq 19 \mathrm{cc}$ in supratentorial DLGG patients [16].

The results reported in these studies with a postoperative follow-up of 6 months were also confirmed in our study, however, with a follow-up period of 18 months. Our data showed an optimum EOR threshold of $\geq 85 \%$ and a residual tumor threshold of $15 \mathrm{~cm}^{3}$ to be associated with a higher likelihood of postoperative seizure control at one year. The epileptogenic focus and the tumor are not always overlapped. Hippocampectomy and corticectomy combined with lesionectomy in patients with DLGG and intractable preoperative tumor related epilepsy have been shown to improve seizure control [24]. The use of intraoperative electrocorticography (ECoG) to identify epileptogenic areas, guide surgical strategy, and improve postoperative seizure control in patients with LGGs still remains inconclusive, mainly due to its low accuracy to detect distant epileptogenic focus and to follow the spreading of epileptic activity [25]. Future intraoperative prospective studies are required to combine the intraoperative use of direct electrical stimulation (DES) and ECoG in order to optimize the DLGG surgery not only in terms of EOR achievable but also for the postoperative seizure outcome. Intraoperative integration between DES and ECoG may allow a supratotal resection, beyond the radiological margins of the tumor, when functionally possible. 
Table 4. Postoperative tumor related epilepsy outcome in DLGGs: Literature review stratified by EOR and 2016 WHO molecular features.

\begin{tabular}{|c|c|c|c|c|c|c|c|c|c|c|c|c|}
\hline Authors & $\begin{array}{l}\mathrm{N} \text { of } \\
\text { Cases }\end{array}$ & $\begin{array}{l}\text { Age at } \\
\text { Surgery } \\
\text { (years) }\end{array}$ & Location & Histology & $\begin{array}{l}\text { Preoperative } \\
\text { Tumor } \\
\text { Volume } \mathrm{cm}^{3}\end{array}$ & EOR & $\begin{array}{l}\text { Preoperative } \\
\text { Seizures }\end{array}$ & $\begin{array}{l}\text { Postoperative } \\
\text { Seizures } \\
\text { (Engel Class I } \\
\text { Outcome) }\end{array}$ & $\begin{array}{c}\text { IDH1/2 } \\
\text { Mutation }\end{array}$ & $\begin{array}{c}1 \mathrm{p} / 19 \mathrm{q} \\
\text { Codeletion }\end{array}$ & $\begin{array}{c}\text { MGMT } \\
\text { Methylation }\end{array}$ & P53+ \\
\hline $\begin{array}{l}\text { Neal A et } \\
\text { Al. 2018 } \\
\text { [21] }\end{array}$ & $\begin{array}{l}70 \text { HGG } \\
\text { and } 30 \\
\text { LGG }\end{array}$ & $50.2 \pm 17.5$ & $\begin{array}{l}\text { Frontal 48; } \\
\text { occipital 1; } \\
\text { parietal 11; } \\
\text { temporal 26 }\end{array}$ & $\begin{array}{c}70 \mathrm{HGG} \\
20 \mathrm{~A} \\
10 \mathrm{O} / \mathrm{OA}\end{array}$ & NA & $\begin{array}{c}15 \text { PR } \\
42 \text { ST } \\
37 \text { GTR } \\
6 \text { unknown } \\
\end{array}$ & $\begin{array}{c}52 \text { cases } \\
(52 \%)\end{array}$ & $\begin{array}{c}58 \text { cases } \\
(58 \%)\end{array}$ & $\begin{array}{c}35 \text { cases } \\
(35 \%)\end{array}$ & NA & NA & NA \\
\hline $\begin{array}{l}\text { Still } \\
\text { M.E.H. et } \\
\text { al. 2018 } \\
\text { [16] }\end{array}$ & 346 LGG & 35.0 & $\begin{array}{c}\text { Frontal 192, } \\
\text { temporal 70, } \\
\text { insular } 41, \\
\text { parietal } 27, \text { other } \\
16\end{array}$ & $\begin{array}{r}48 \mathrm{~A} \\
298 \mathrm{O}\end{array}$ & NA & $\begin{array}{c}100 \% 50 \text { cases; } \\
90 \%-99 \% 92 \\
\text { cases; } 50 \%-89 \% \\
134 \text { cases; } \\
<50 \% 70 \text { cases }\end{array}$ & $\begin{array}{c}346 \text { cases } \\
(100 \%)\end{array}$ & $\begin{array}{l}227 \text { cases } \\
(65.60 \%)\end{array}$ & $\begin{array}{c}19 \text { (21 cases } \\
\text { tested) } \\
(90.47 \%)\end{array}$ & $\begin{array}{c}65(206 \\
\text { cases tested) } \\
(31.55 \%)\end{array}$ & NA & NA \\
\hline $\begin{array}{l}\text { Xu DS et } \\
\text { al. } 2018 \\
{[17]}\end{array}$ & 128 LGG & 40.8 & $\begin{array}{c}\text { Frontal 74, } \\
\text { parietal 34, } \\
\text { temporal 45, } \\
\text { occipital 8, } \\
\text { insular 17, deep } 6 \\
\end{array}$ & $\begin{array}{c}18 \mathrm{~A} \\
86 \mathrm{O} \\
24 \mathrm{OA}\end{array}$ & 57,5 & $\begin{array}{c}90 \%-99 \% \\
64 \text { cases; } \\
80 \%-89 \% \\
11 \text { cases }\end{array}$ & $\begin{array}{c}128 \text { cases } \\
(100 \%)\end{array}$ & $\begin{array}{l}105 \text { cases } \\
(82.03 \%)\end{array}$ & NA & $\begin{array}{l}25 \text { cases } \\
(19.53 \%)\end{array}$ & NA & NA \\
\hline $\begin{array}{l}\text { Chen H et } \\
\text { al. 2017 } \\
\text { [19] }\end{array}$ & $\begin{array}{c}712 \\
\text { GLIOMA }\end{array}$ & $\begin{array}{c}54 \\
(60.7-53.4)\end{array}$ & $\begin{array}{c}\text { Temporal } 191 \\
\text { non temporal } 521\end{array}$ & $\begin{array}{c}77 \text { WHO II, } 128 \\
\text { WHO III, } 507 \text { WHO } \\
\text { IV }\end{array}$ & NA & NA & $\begin{array}{l}276 \text { cases } \\
(38.76 \%)\end{array}$ & NA & $\begin{array}{l}177 \text { cases } \\
(16.43 \%)\end{array}$ & $\begin{array}{l}644 \text { cases } \\
(90.44 \%)\end{array}$ & NA & NA \\
\hline $\begin{array}{l}\text { Zhong Z. } \\
\text { et al. 2015 } \\
\text { [23] }\end{array}$ & 311 LGG & 38 & NA & $\begin{array}{c}140 \mathrm{~A} \\
140 \mathrm{OA} \\
31 \mathrm{O}\end{array}$ & NA & NA & $\begin{array}{l}183 \text { cases } \\
(58.84 \%)\end{array}$ & $\begin{array}{l}211 \text { cases } \\
(67.84 \%)\end{array}$ & $\begin{array}{l}257 \text { cases } \\
(82.63 \%)\end{array}$ & NA & NA & NA \\
\hline $\begin{array}{l}\text { Yang Y. et } \\
\text { al. 2015 } \\
\text { [22] }\end{array}$ & $\begin{array}{l}\text { 6 LGG } \\
106 \text { HGG }\end{array}$ & $\begin{array}{c}34 \\
(39.8-42.2)\end{array}$ & $\begin{array}{l}88 \text { frontal; } 74 \\
\text { temporal; } 45 \\
\text { parietal; } 11 \\
\text { occipital; } 17 \\
\text { insular }\end{array}$ & $\begin{array}{l}64 \text { WHO II } \\
58 \text { WHO III } \\
48 \text { WHO IV }\end{array}$ & $\begin{array}{c}4.7 \mathrm{~cm}(5.6-6.4 \\
\mathrm{cm})\end{array}$ & NA & $\begin{array}{l}74 \text { cases } \\
(42.3 \%)\end{array}$ & NA & $\begin{array}{c}41 \text { WHO II } \\
\text { cases (64.0\%); } \\
33 \text { WHO III } \\
\text { cases (56.8\%); } \\
10 \text { WHO IV } \\
\text { cases }(20.8 \%)\end{array}$ & NA & NA & $\begin{array}{c}24 \text { WHO II } \\
\text { cases }(37.5 \%) ; \\
28 \text { WHO III } \\
\text { cases }(48.2 \%) ; \\
25 \text { WHO IV } \\
\text { cases }(52.0 \%)\end{array}$ \\
\hline $\begin{array}{l}\text { Ius et al. } \\
2014 \text { [15] }\end{array}$ & $\begin{array}{c}52 \\
\text { LGG }\end{array}$ & 38.73 & $\begin{array}{l}\text { Insula; left 36, } \\
\text { right } 16\end{array}$ & $\begin{array}{l}32 \mathrm{~A} \\
11 \mathrm{OA} \\
9 \mathrm{O}\end{array}$ & 75.42 & $\begin{array}{c}87 \% \\
>90 \% 21 \text { cases } \\
70-89 \% 23 \text { cases } \\
<70 \% 8 \text { cases }\end{array}$ & NA & $\begin{array}{l}35 \text { cases } \\
(67.30 \%)\end{array}$ & NA & NA & NA & NA \\
\hline $\begin{array}{l}\text { Mulligan } \\
\text { L. et al. } \\
2014 \text { [20] }\end{array}$ & 62 LGG & NA & NA & $62 \mathrm{O}$ & $\begin{array}{l}4 \text { groups: } \\
45 \mathrm{~mm} \\
46 \mathrm{~mm} \\
56 \mathrm{~mm} \\
37.5 \mathrm{~mm}\end{array}$ & NA & $\begin{array}{l}48 \text { cases } \\
(77.41 \%)\end{array}$ & NA & $\begin{array}{l}48 \text { cases } \\
(77.41 \%)\end{array}$ & $\begin{array}{l}39 \text { cases } \\
(62.90 \%)\end{array}$ & NA & $\begin{array}{l}24 \text { cases } \\
(38.70 \%)\end{array}$ \\
\hline
\end{tabular}


Table 4. Cont.

\begin{tabular}{|c|c|c|c|c|c|c|c|c|c|c|c|c|}
\hline Authors & $\begin{array}{l}\mathrm{N} \text { of } \\
\text { Cases }\end{array}$ & $\begin{array}{l}\text { Age at } \\
\text { Surgery } \\
\text { (years) }\end{array}$ & Location & Histology & $\begin{array}{l}\text { Preoperative } \\
\text { Tumor } \\
\text { Volume } \mathrm{cm}^{3}\end{array}$ & EOR & $\begin{array}{l}\text { Preoperative } \\
\text { Seizures }\end{array}$ & $\begin{array}{l}\text { Postoperative } \\
\text { Seizures } \\
\text { (Engel Class I } \\
\text { Outcome) }\end{array}$ & $\begin{array}{c}\text { IDH1/2 } \\
\text { Mutation }\end{array}$ & $\begin{array}{c}1 \mathrm{p} / 19 \mathrm{q} \\
\text { Codeletion }\end{array}$ & $\begin{array}{c}\text { MGMT } \\
\text { Methylation }\end{array}$ & P53+ \\
\hline $\begin{array}{l}\text { Liubinas } \\
\text { SV et al. } \\
2014 \text { [8] }\end{array}$ & 30 LGG & 35.4 years & NA & $\begin{array}{c}22 \mathrm{~A} \\
6 \mathrm{OA} \\
1 \text { mixed OA and } \\
\text { protoplasmic } \\
\text { astrocytoma } \\
1 \mathrm{O}\end{array}$ & $\begin{array}{c}4 \text { groups: } 45 \\
\mathrm{~mm}, 46 \mathrm{~mm}, 56 \\
\mathrm{~mm}, 37.5 \mathrm{~mm}\end{array}$ & NA & $\begin{array}{l}23 \text { cases } \\
(76.66 \%)\end{array}$ & NA & $\begin{array}{l}17 \text { cases } \\
(56.66 \%\end{array}$ & NA & NA & NA \\
\hline $\begin{array}{l}\text { Pallud J et } \\
\text { al. 2014 } \\
\text { [7] }\end{array}$ & 1509 LGG & $\begin{array}{c}<30 \mathrm{yrs}= \\
390 \text { cases } \\
30-45 \text { yrs } \\
=726 \\
\text { cases }\end{array}$ & NA & $\begin{array}{c}327 \mathrm{~A} \\
781 \text { OA } \\
280 \text { mixed glioma } \\
121 \text { missing }\end{array}$ & NA & $\begin{array}{c}<100 \mathrm{~cm}^{3} 808 \\
\text { cases }(53.54 \%) \\
>100 \mathrm{~cm}^{3} \\
346 \text { cases } \\
(22.92 \%) \\
\text { missing cases } \\
355 \\
(23,54)\end{array}$ & NA & NA & NA & NA & NA & NA \\
\hline
\end{tabular}

$\mathrm{A}=$ astrocytoma; $\mathrm{EOR}=$ extent of resection: GTR $=$ gross-total resection; HGG $=$ high grade glioma; LGG = low grade glioma; $\mathrm{NA}=$ not applicable; $\mathrm{PR}=$ partial resection: $\mathrm{OA}=$ oligoastrocitoma; $\mathrm{O}=$ oligodendroglioma; $\mathrm{STR}=$ subtotal resection 


\subsection{The Tumor Growth Pattern Influences the Postoperative Seizure Outcome}

Changes in peritumoral tissue are involved in in the pathogenesis of tumor-related epilepsy $[1,2,6$, $8,15,26,27]$.

Furthermore, during the sprouting of tumor cells in normal tissue, glioma cells release a high level of glutamate into the extracellular space. As a consequence, an imbalance between inhibitory and excitatory mechanisms is induced, generating neuron cell death, and promoting the migration of tumor cells $[6,27]$.

As previously described, the preoperative $\triangle \mathrm{T} 2 \mathrm{~T} 1 \mathrm{MRI}$ index provides an imaging estimate of tumor growing pattern prevalence and the EOR achievable [12,15].

Kinetic analysis in low grade gliomas highlighted that tumor growth results from two main mechanisms: proliferation and diffusion $[28,29]$.

The prevalence of proliferation growth leads to a bulky tumor with a regular shape, determining similar tumor volume in both post-contrast T1-weighted MRI and T2-weighted preoperative MRI sequences; whereas the prevalence of the diffusive growth generates the tumor infiltration along the white matter, resulting in a complex shape with digitations more visible on T2-weighted images and less amenable of an extensive tumor resection $[28,29]$.

Higher level of preoperative $\Delta \mathrm{T} 2 \mathrm{~T} 1 \mathrm{MRI}$ index thus represents the prevalence of the diffusive growing mechanism.

In this study, we confirmed the role played by the tumor growth pattern (proliferative versus diffusive), expressed by $\Delta \mathrm{T} 2 \mathrm{~T} 1 \mathrm{MRI}$ index on postoperative seizure outcome [15].

As a new feature, we provided a predictive cut-off value by the receiver operating characteristic (ROC) analysis.

According to ROC analysis, the optimum $\triangle \mathrm{T} 2 \mathrm{~T} 1 \mathrm{MRI}$ index threshold $\leq 18 \mathrm{~cm}^{3}$ was associated with a higher likelihood of long-term seizure control. Otherwise patients with a $\Delta \mathrm{T} 2 \mathrm{~T} 1 \mathrm{MRI}$ index $>18 \mathrm{~cm}^{3}$ had a higher likelihood of postoperative seizure persistence at 18 months.

Assuming that the preoperative $\Delta \mathrm{T} 2 \mathrm{~T} 1 \mathrm{MRI}$ index higher than $18 \mathrm{~cm}^{3}$ reflects the prevalence of the diffusive and infiltrative tumor component, it could constitute an indirect imaging evaluation of changes in peritumoral tissue induced by tumor growth.

When the diffusive mechanism is predominant, tumor infiltrates the functional area limiting the resection, thus $\triangle \mathrm{T} 2 \mathrm{~T} 1 \mathrm{MRI}$ index may provide a potentially estimation of the epileptic network development, allowing the preoperative detection of patients at greater risk of postoperative seizure persistence.

\subsection{It is a Matter of Interaction between EOR and Tumor Growth Pattern}

The simultaneous role played by the EOR and the $\triangle \mathrm{T} 2 \mathrm{~T} 1 \mathrm{MRI}$ index in postoperative seizure outcome could reflect the relationship between the extent of resection achievable and the tumor growing pattern. The $\triangle \mathrm{T} 2 \mathrm{~T} 1 \mathrm{MRI}$ index is the prognostic preoperative index of EOR itself, while the EOR is inversely related to the tumor growth pattern, as demonstrated in our previous study [12,15].

We can thus assume that the less infiltrative the tumor growth pattern is, the better the chances of greater EOR are and, consequently, the better the postoperative seizure control is.

Regarding the molecular assessment, only a few investigations have focused on the role played by the molecular biomarkers on postoperative seizure outcome in DLGG patients, reaching divergent results [21,23].

In a recent investigation, Neal et al. found a strong relationship between the higher IDH1-R132H rates and a severe postoperative seizure outcome, although the contribution to tumor related epilepsy by IDH $1 / 2$ mutation is not clear [21].

In contrast, Zhong et al. reported no significant difference in IDH status and seizure outcomes in 222 patients with WHO grade II gliomas [23].

In our study, when comparing seizure outcomes in patients with oligodendrogliomas and with astrocytomas (based on the 2016 WHO update), the majority of patients with oligodendrogliomas 
were Engel Class IA in comparison with patients with astrocytoma IDH1/2 mutated or astrocytoma IDH1/2 wild type $(81.82 \%, 68.89 \%$, and $50 \%$, respectively; $p=0.001)$. It is likely that LGGs, which show less infiltrative growth, as oligodendrogliomas, are less prone to modify the tumor microenvironment, comparing to infiltrative lesions. Thus, electrical signaling of peritumoral tissues may be less impaired in oligodendrogliomas [20].

As a further confirmation regarding the role of EOR on seizure outcome, the Cox analysis revealed that the tumor molecular class did not result as an independent predictor at multivariate analysis, suggesting that EOR and the peritumoral infiltrative component are more important in predicting the outcome of epilepsy. Considering that the $\Delta \mathrm{T} 2 \mathrm{~T} 1 \mathrm{MRI}$ index represents the infiltrative component of the tumor, it could be an indirect index of changes in peritumoral tissue induced by tumor growth and infiltration $[15,26,27]$. This index may be considered as a measure of persistent epileptogenic process after surgery. It is interesting to note that patients with prevalence of infiltrative tumor growing pattern, which means $\Delta \mathrm{T} 2 \mathrm{~T} 1 \mathrm{MRI}$ index higher than $18 \mathrm{~cm}^{3}$, had a worse seizure outcome $(66 \%$ of patient in Engel Class IB-IV, Figure 1B) and expressed the IDH1-2 mutation in more than $90 \%$ of cases. Huberfeld et al., in 2016, explained the relationship between epilepsy in glioma and IDH1/2 expression.

The epileptic discharge and tumor proliferation can be traced back to an imbalance in glutamate transporters determining an increase in concentrations of extracellular glutamate [6]. The presence of IDH mutated cells can explain seizure persistence in patients with a reduced EOR and high $\Delta \mathrm{T} 2 \mathrm{~T} 1$ MRI index in the IDH-mutated tumors.

This hypothesis may explain the negative epileptic outcome in patient with higher $\Delta \mathrm{T} 2 \mathrm{~T} 1 \mathrm{MRI}$ index. Indeed, at multivariate analysis, the $\Delta \mathrm{T} 2 \mathrm{~T} 1 \mathrm{MRI}$ index $(p=0.016)$ resulted as a stronger predictor of postoperative outcome in comparison with $\operatorname{EOR}(p=0.030)$, underlying the importance of the infiltrative tumor component, which is generally not removed because it is functional, in seizure persistence. The availability of predictive factors for postoperative seizure outcome could provide a useful tool to guide therapeutic antiepileptic strategy after surgery, avoiding pharmacological overtreatment improving the patients' quality of life.

\subsection{Limitation and Future Directions}

There are several limitations of our study. The most important one is based on the retrospective nature of the investigation

The peritumoral cortex may contain epileptogenic foci, which may directly affect postoperative seizure control $[8,24,30]$. Future studies are thus required to better investigate the correlation between supra-total resection, when functionally achievable, and seizure outcome.

Although in the present study gliomas were classified accordingly to the currently used 2016 WHO classification of the brain tumors, it is desirable in the future to molecularly characterize diffuse astrocytic gliomas, IDH-wildtype, in order to recognize those that can indeed be classified as diffuse astrocytic glioma, IDH-wildtype, with molecular features of glioblastoma, WHO grade IV $[31,32]$. Additional information deriving from next generation sequencing analysis would help stratify postoperative seizure outcome in DLGGs, using markers with known pathophysiological roles in epilepsy such as glutamate metabolism/clearance [5].

In the pattern of results reported, the cognitive statuses of the patients were not considered. The impact of tumor related epilepsy on the pre-surgical neuropsychological examination could prove to be useful to better assess the effects of tumor growth itself and the influence of tumor related epilepsy or medication on the cognitive status of the patients. It has been shown that DLGG patients can present emotional and personality changes in their post-surgery examination [33]. An important aspect would be analyzing the effects of tumor related epilepsy on the post-surgery quality of life of patients in terms of emotional processing and personality.

In closing, considering the lack of standardized protocol for tumor related epilepsy management, both before and after surgery, it should be important to plan a multidisciplinary approach considering the complex therapeutic profile of DLGGs patients [34]. In detail, a preoperative study as for epilepsy 
surgery with prolong Video-EEG recordings for patients with tumor related epilepsy characterized by complex semiology not directly associated with tumor location, could be useful in future studies to assess the spreading of epileptic discharges and plan the function possibility of resection and the intra-operative position of the strips.

A tailored AEDs treatment should be adopted for each patient, considering that changes in seizure type or worsening in Engel Class could be related to tumor progression. There are numerous points of interest to be noted: homogeneous data collection in a monoinstutional case-series; strict definition of postoperative seizure control as Engel Class A patients; postoperative seizure follow-up at 18 months after surgery concomitant with control MRI, to rule out cases with tumor progression; integration of tumor volumetric data and molecular data, according to $2016 \mathrm{WHO}$ classification, to stratify postoperative seizure outcome; ROC analysis to determine EOR, residual tumor volume, and $\triangle \mathrm{T} 2 \mathrm{~T} 1 \mathrm{MRI}$ index corresponding to optimal seizure outcome.

\section{Materials and Methods}

\subsection{Study Population}

A total of 155 adult patients with tumor related epilepsy underwent surgery at our institution for primary DLGG (January 2007-May 2018).

Seizures were the onset symptom and all patients developed seizure not fully controlled with medical treatment before surgery. At least two AEDs were given in successive monotherapies or together in politherapy, resulting in a drug-resistant epilepsy, according to the International League Against Epilepsy (ILAE) definition [35].

The 2017 ILAE classification was applied to classify the type of seizures [36].

Patients were enrolled according to the following criteria: age $\geq 18$ years; preoperative MRI suggestive of supratentorial low grade glioma; no previous surgery, chemo- or radio-therapy; at least 18 months of follow up, with concomitant MRI control, to rule out cases with tumor progression. Objective evaluation of EOR preoperatively and postoperatively on MRI images in DICOM format based on T2-weighted MRI sequences; revision of histopathological specimens by using the new 2016 WHO Classification; diagnosis of drug-resistant tumor related epilepsy, according to the ILAE definition [37].

Patients were evaluated preoperatively, at discharge and, during the follow up, every 6 months. Engel Class at 18-month follow-up was used to compute predictors of postoperative seizure outcome [36].

No patient underwent adjuvant therapy with radiotherapy or chemotherapy during the period of postoperative follow-up.

The local Ethics Committee, Comitato Etico Unico Regionale del Friuli Venezia Giulia, approved this investigation (protocol N.0036567/P/GEN/EGAS, ID study 2540). Considering that the study was retrospective, written consent to participate in the study was not applicable. Written informed consent was obtained for surgery.

\subsection{Surgical Procedure}

All patients were surgically treated with the aim of the intraoperative brain mapping technique both at cortical and subcortical level [38].

The awake surgery protocol was selected following the standard protocol previously described [39].

\subsection{Volumetric Analysis}

Tumor volume data were obtained by analyzing structural imaging data routinely acquired during pre-surgery and post-surgical investigations in axial 3D T2-weighted and 3D post-contrast T1-weighted MRI slices. All tumor segmentations were realized by using the OSIRIX software tool 
(GNU LESSER, General Public License, Geneva, Switzerland) [40,41]. Specifically, the tumor growing pattern, expressed by MRI $\Delta \mathrm{T} 2 \mathrm{~T} 1$ index, and EOR were computed as previously described [12,15].

Briefly, the tumor growing pattern and the EOR were assessed as listed: (1) preoperative tumor volume segmented on axial T2-weighted MRI images-preoperative tumor volume segmented on axial T1-weighted images. (2) (preoperative tumor volume-postoperative tumor volume)/(preoperative tumor volume) in axial T2-weighted MRI axial images.

\subsection{Histological and Molecular Analysis}

Histological and molecular data were retrospectively analyzed according to the 2016 WHO classification [42].

Immunohistochemistry (IHC) for Ki67 and IDH1R132H, fluorescence in situ hybridization (FISH) to evaluate $1 \mathrm{p} / 19 \mathrm{q}$ codeletion and analysis of the genetic status of O6-methylguanine-DNA-methyltransferase (MGMT) promoter and isocitrate dehydrogenase (IDH1/2) genes were performed as previously described. Gliomas were classified as methylated when the average percentage of methylation of $\mathrm{CpG}$ islands was $\geq 8 \%$ [43].

\subsection{Statistical Analysis}

Categorical variables were reported as percentages, continuous variables were reported as mean \pm standard deviation or median and range as appropriate, according with the data distribution. Normality of the continuous variables was tested using the Shapiro-Wilk test, the $t$-test or Mann-Whitney U-test as appropriate, was used to compare continuous variables between groups. For the outcome analysis, Engel classification was dichotomized as Class IA versus Class IB-IV (patients were either completely seizure free or not completely seizure free). In univariate analysis, the variables considered as possible prognostic factors were age, sex, preoperative tumor volume, tumor histological subtype, molecular markers, tumor side, preoperative seizures feature, seizure onset characteristics and frequency, time between seizure onset and surgery, intraoperative protocol used, EOR, residual tumor volume, and preoperative $\triangle \mathrm{T} 2 \mathrm{~T} 1 \mathrm{MRI}$ index.

Multivariate stepwise backward analyses included all variables significant at $p=0.05$ in univariate analysis. The results were presented as odds ratios and $95 \%$ confidence intervals.

For EOR, preoperative $\triangle \mathrm{T} 2 \mathrm{~T} 1 \mathrm{MRI}$ index and residual tumor threshold, the cut-off values able to discriminate, with high sensitivity and specificity, the postoperative seizure control, was determined by De Long's nonparametric receiver operating characteristic (ROC) analysis with exact binomial estimation of confidence intervals (CI) of the area under the curve (AUC).

All analyses were conducted using Stata/SE (version 14.0 Stata Corp.) for Mac. All two-tailed statistical significance levels were set at $p<0.05$.

\section{Conclusions}

The association between a worse seizure outcome and the prevalence of an infiltrating tumor growing pattern expressed by high $\Delta \mathrm{T} 2 \mathrm{~T} 1 \mathrm{MRI}$ index reinforces evidence of common mechanisms underlying both epileptogenesis and tumor growth.

The individual evaluation of the tumor growing pattern and the estimation of the EOR may thus represent a helpful tool in the early identification of patients with an increased risk of seizure persistence after surgery.

Tumor volumetric information could be useful when deciding and discussing prognosis and potential postoperative seizure outcomes to better handle the entire management, starting from pre- to post surgery.

Considering the role of IDH 1/2 mutation in both tumor growing and epileptogenesis, and considering that up to $80 \%$ of DLGGs carried out this mutation [44], potential future goals could be represented in the development of anti-epileptic drugs targeting the underlying biochemical pathology related to the mutation of IDH $1 / 2$. 
Author Contributions: Conceptualization, T.I.; Data curation, T.I., G.P., B.T., R.B., D.C. and C.L.; Formal analysis, T.I. and M.I.; Methodology, T.I. and M.I.; Software, M.M. and M.I.; Supervision, T.I., G.P., B.T. and M.S.; Validation, T.I. and G.P.; Visualization, M.M.; Writing—original draft, T.I. and G.P.; Writing—review and editing, T.I., G.P., B.T., M.M., R.B., M.I., D.C., C.L. and M.S. All authors have read and agreed to the published version of the manuscript.

Funding: This research received no external funding.

Acknowledgments: We acknowledge the support by the staff of the Medical Imaging Centre.

Conflicts of Interest: The authors declare no conflict of interest.

\section{References}

1. Aronica, E.; Leenstra, S.; van Veelen, C.W.; van Rijen, P.C.; Hulsebos, T.J.; Tersmette, A.C.; Yankaya, B.; Troost, D. Glioneuronal tumors and medically intractable epilepsy: A clinical study with long-term follow-up of seizure outcome after surgery. Epilepsy. Res. 2001, 43, 179-191. [CrossRef]

2. Rudà, R.; Trevisan, E.; Soffietti, R. Epilepsy and brain tumors. Curr. Opin. Oncol. 2010, 22, 611-620. [CrossRef] [PubMed]

3. Rossetti, A.O.; Stupp, R. Epilepsy in brain tumor patients. Curr. Opin. Neurol. 2010, 23, 603-609. [CrossRef] [PubMed]

4. Rudà, R.; Bello, L.; Duffau, H.; Soffietti, R. Seizures in low-grade gliomas: Natural history, pathogenesis, and outcome after treatments. Neuro. Oncol. 2012, 14 (Suppl. 4), iv55-iv64. [CrossRef]

5. Vecht, C.J.; Wagner, G.L.; Wilms, E.B. Treating seizures in patients with brain tumors: Drug interactions between antiepileptic and chemotherapeutic agents. Semin. Oncol. 2003, 30 (Suppl. 19), 49-52. [CrossRef]

6. Huberfeld, G.; Vecht, C.J. Seizures and gliomas-towards a single therapeutic approach. Nat. Rev. Neurol. 2016, 12, 204-216. [CrossRef]

7. Pallud, J.; Audureau, E.; Blonski, M.; Sanai, N.; Bauchet, L.; Fontaine, D.; Mandonnet, E.; Dezamis, E.; Psimaras, D.; Guyotat, J.; et al. Epileptic seizures in diffuse low-grade gliomas in adults. Brain 2014, 137 Pt 2, 449-462. [CrossRef]

8. Liubinas, S.V.; D’Abaco, G.M.; Moffat, B.M.; Gonzale, M.; Feleppa, F.; Nowell, C.J.; Gorelik, A.; Drummond, K.J.; O’Brien, T.J.; Kaye, A.H.; et al. IDH1 mutation is associated with seizures and protoplasmic subtype in patients with low-grade gliomas. Epilepsia 2014, 55, 1438-1443. [CrossRef]

9. Zhang, C.B.; Bao, Z.S.; Wang, H.J.; Yan, W.; Liu, Y.W.; Li, M.Y.; Zhang, W.; Chen, L.; Jiang, T. Correlation of IDH1/2 mutation with clinicopathologic factors and prognosis in anaplastic gliomas: A report of 203 patients from China. J. Cancer. Res. Clin. Oncol. 2014, 140, 45-51. [CrossRef]

10. Sanai, N.; Berger, M.S. Surgical oncology for gliomas: The state of the art. Nat. Rev. Clin. Oncol. 2018, 15, 112-125. [CrossRef]

11. Capelle, L.; Fontaine, D.; Mandonnet, E.; Taillandier, L.; Golmard, J.L.; Bauchet, L.; Pallud, J.; Peruzzi, P.; Baron, M.H.; Kujas, M.; et al. Spontaneous and therapeutic prognostic factors in adult hemispheric World Health Organization Grade II gliomas: A series of 1097 cases: Clinical article. J. Neurosurg. 2013, 118, 1157-1168. [CrossRef] [PubMed]

12. Ius, T.; Isola, M.; Budai, R.; Pauletto, G.; Tomasino, B.; Fadiga, L.; Skrap, M. Low-grade glioma surgery in eloquent areas: Volumetric analysis of extent of resection and its impact on overall survival. A single-institution experience in 190 patients: Clinical article. J. Neurosurg. 2012, 117, 1039-1052. [CrossRef] [PubMed]

13. McGirt, M.J.; Chaichana, K.L.; Attenello, F.J.; Weingart, J.D.; Than, K.; Burger, P.C.; Olivi, A.; Brem, H.; Quinoñes-Hinojosa, A. Extent of surgical resection is independently associated with survival in patients with hemispheric infiltrating low-grade gliomas. Neurosurgery 2008, 63, 700-707. [CrossRef] [PubMed]

14. Smith, J.S.; Chang, E.F.; Lamborn, K.R.; Chang, S.M.; Prados, M.D.; Cha, S.; Tihan, T.; Vandenberg, S.; McDermott, M.W.; Berger, M.S. Role of extent of resection in the long-term outcome of low-grade hemispheric gliomas. J. Clin. Oncol. 2008, 26, 1338-1345. [CrossRef] [PubMed]

15. Ius, T.; Pauletto, G.; Isola, M.; Gregoraci, G.; Budai, R.; Lettieri, C.; Eleopra, R.; Fadiga, L.; Skrap, M. Surgery for insular low-grade glioma: Predictors of postoperative seizure outcome. J. Neurosurg. 2014, 120, 12-23. [CrossRef] 
16. Still, M.E.H.; Roux, A.; Huberfeld, G.; Bauchet, L.; Baron, M.H.; Fontaine, D.; Blonski, M.; Mandonnet, E.; Guillevin, R.; Guyotat, J.; et al. Extent of Resection and Residual Tumor Thresholds for Postoperative Total Seizure Freedom in Epileptic Adult Patients Harboring a Supratentorial Diffuse Low-Grade Glioma. Neurosurgery 2018, 85, 332-340. [CrossRef]

17. Xu, D.S.; Awad, A.W.; Mehalechko, C.; Wilson, J.R.; Ashby, L.S.; Coons, S.W.; Sanai, N. An extent of resection threshold for seizure freedom in patients with low-grade gliomas. J. Neurosurg. 2018, 128, 1084-1090. [CrossRef]

18. Englot, D.J.; Wang, D.D.; Rolston, J.D.; Shih, T.T.V.; Chang, E.F. Rates and predictors of long-term seizure freedom after frontal lobe epilepsy surgery: A systematic review and meta-analysis. J. Neurosurg. 2012, 116, 1042-1048. [CrossRef]

19. Chen, H.; Judkins, J.; Thomas, C.; Wu, M.; Khoury, L.; Benjamin, C.G.; Pacione, D.; Golfinos, J.G.; Kumthekar, P.; Ghamsari, F.; et al. Mutant IDH1 and seizures in patients with glioma. Neurology 2017, 88, 1805-1813. [CrossRef]

20. Mulligan, L.; Ryan, E.; O’Brien, M.; Looby, S.; Heffernan, J.; O’Sullivan, J.; Clarke, M.; Buckley, P.; O’Brien, D.; Farrell, M.; et al. Genetic features of oligodendrogliomas and presence of seizures. The relationship of seizures and genetics in LGOs. Clin. Neuropathol. 2014, 33, 292-298. [CrossRef]

21. Neal, A.; Kwan, P.; O’Brien, T.J.; Buckland, M.E.; Gonzales, M.; Morokoff, A. IDH1 and IDH2 mutations in postoperative diffuse glioma-associated epilepsy. Epilepsy. Behav. 2018, 78, 30-36. [CrossRef] [PubMed]

22. Yang, Y.; Mao, Q.; Wang, X.; Liu, Y.; Mao, Y.; Zhou, Q.; Luo, J. An analysis of 170 glioma patients and systematic review to investigate the association between IDH-1 mutations and preoperative glioma-related epilepsy. J. Clin. Neurosci. 2016, 31, 56-62. [CrossRef] [PubMed]

23. Zhong, Z.; Wang, Z.; Wang, Y.; You, G.; Jiang, T. IDH1/2 mutation is associated with seizure as an initial symptom in low-grade glioma: A report of 311 Chinese adult glioma patients. Epilepsy. Res. 2015, 109, 100-105. [CrossRef] [PubMed]

24. Ghareeb, F.; Duffau, H. Intractable epilepsy in paralimbic Word Health Organization Grade II gliomas: Should the hippocampus be resected when not invaded by the tumor? J. Neurosurg. 2012, 116, 1226-1234. [CrossRef]

25. Roessler, K.; Heynold, E.; Buchfelder, M.; Stefa, H.; Hamer, H.M. Current value of intraoperative electrocorticography (iopECoG). Epilepsy. Behav. 2019, 91, 20-24. [CrossRef] [PubMed]

26. Shamji, M.F.; Fric-Shamji, E.C.; Benoit, B.G. Brain tumors and epilepsy: Pathophysiology of peritumoral changes. Neurosurg. Rev. 2009, 32, 275-284. [CrossRef] [PubMed]

27. You, G.; Sha, Z.; Jiang, T. The pathogenesis of tumor-related epilepsy and its implications for clinical treatment. Seizure 2012, 21, 153-159. [CrossRef]

28. Skrap, M.; Mondani, M.; Tomasino, B.; Weis, L.; Budai, R.; Pauletto, G.; Eleopra, R.; Fadiga, L.; Ius, T. Surgery of insular nonenhancing gliomas: Volumetric analysis of tumoral resection, clinical outcome, and survival in a consecutive series of 66 cases. Neurosurgery 2012, 70, 1081-1094. [CrossRef]

29. Mandonnet, E.; Capelle, L.; Duffau, H. Extension of paralimbic low grade gliomas: Toward an anatomical classification based on white matter invasion patterns. J. Neurooncol. 2006, 78, 179-185. [CrossRef]

30. Pallud, J.; Le Van Quyen, M.; Bielle, F.; Pellegrino, C.; Varlet, P.; Cresto, N.; Baulac, M.; Duyckaerts, C.; Kourdougli, N.; Chazal, G.; et al. Cortical GABAergic excitation contributes to epileptic activities around human glioma. Sci. Transl. Med. 2014, 6, 244-289. [CrossRef]

31. Louis, D.N.; Ellison, D.W.; Brat, D.J.; Aldape, K.; Capper, D.; Hawkins, C.; Paulus, W.; Perry, A.; Reifenberger, G.; Figarella-Branger, D.; et al. cIMPACT-NOW: A practical summary of diagnostic points from Round 1 updates. Brain Pathol. 2019, 29, 469-472. [PubMed]

32. Brat, D.J.; Aldape, K.; Colman, H.; Holland, E.C.; Louis, D.N.; Jenkins, R.B.; Kleinschmidt-DeMasters, B.K.; Perry, A.; Reifenberger, G.; Stupp, R.; et al. cIMPACT-NOW update 3: Recommended diagnostic criteria for "Diffuse astrocytic glioma, IDH-wildtype, with molecular features of glioblastoma, WHO grade IV". Acta Neuropathol. 2018, 136, 805-810. [CrossRef] [PubMed]

33. Campanella, F.; Fabbro, F.; Ius, T.; Shallice, T.; Skrap, M. Acute effects of surgery on emotion and personality of brain tumor patients: Surgery impact, histological aspects, and recovery. Neuro. Oncol. 2015, 17, 1121-1131. [CrossRef] [PubMed] 
34. Maschio, M.; Aguglia, U.; Avanzini, G.; Banfi, P.; Buttinelli, C.; Capovilla, G.; Casazza, M.M.L.; Colicchio, G.; Coppola, A.; Costa, C.; et al. Brain Tumor-related Epilepsy study group of Italian League Against Epilepsy (LICE). Management of epilepsy in brain tumors. Neurol. Sci. 2019, 40, 2217-2234. [CrossRef]

35. Kwan, P.; Arzimanoglou, A.; Berg, A.T.; Brodie, M.J.; Allen Hauser, W.; Mathern, G.; Moshé, S.L.; Perucca, E.; Wiebe, S.; French, J. Definition of drug resistant epilepsy: Consensus proposal by the ad hoc Task Force of the ILAE Commission on Therapeutic Strategies. Epilepsia 2010, 51, 1069-1077. [CrossRef]

36. Fisher, R.S.; Cross, J.H.; French, J.A.; Higurashi, N.; Hirsch, E.; Jansen, F.E.; Lagae, L.; Moshé, S.L.; Peltola, J.; Roulet Perez, E.; et al. Operational classification of seizure types by the International League Against Epilepsy: Position Paper of the ILAE Commission for Classification and Terminology. Epilepsia 2017, 58, 522-530. [CrossRef]

37. Engel, J., Jr.; Burchfiel, J.; Ebersole, J.; Gates, J.; Gotman, J.; Homan, R.; Ives, J.; King, D.; Lieb, J.; Sato, S.; et al. Long-term monitoring for epilepsy. Report of an IFCN committee. Electroencephalogr. Clin. Neurophysiol. 1993, 87, 437-458. [CrossRef]

38. Berger, M.S.; Ojemann, G.A. Intraoperative brain mapping techniques in neuro-oncology. Stereotact. Funct. Neurosurg. 1992, 58, 153-161. [CrossRef]

39. Skrap, M.; Marin, D.; Ius, T.; Fabbro, F.; Tomasino, B. Brain mapping: A novel intraoperative neuropsychological approach. J. Neurosurg. 2016, 125, 877-887. [CrossRef]

40. Ius, T.; Angelini, E.; Thiebaut de Schotten, M.; Mandonnet, E.; Duffau, H. Evidence for potentials and limitations of brain plasticity using an atlas of functional resectability of WHO grade II gliomas: Towards a "minimal common brain". Neuroimage 2011, 56, 992-1000. [CrossRef]

41. Rosset, A.; Spadola, L.; Ratib, O. OsiriX: An open-source soft- ware for navigating in multidimensional DICOM images. J. Digit. Imaging 2004, 17, 205-216. [CrossRef] [PubMed]

42. Louis, D.N.; Perry, A.; Reifenberger, G.; von Deimling, A.; Figarella-Branger, D.; Cavenee, W.K.; Ohgaki, H.; Wiestler, O.D.; Kleihues, P.; Ellison, D.W. The 2016 World Health Organization Classification of Tumors of the Central Nervous System: A summary. Acta Neuropathol. 2016, 131, 803-820. [CrossRef] [PubMed]

43. Preusser, M.; Berghoff, A.S.; Manzl, C.; Filipits, M.; Weinhäusel, A.; Pulverer, W.; Dieckmann, K.; Widhalm, G.; Wöhrer, A.; Knosp, E.; et al. Clinical Neuropathology practice news 1-2014: Pyrosequencing meets clinical and analytical performance criteria for routine testing of MGMT promoter methylation status in glioblastoma. Clin. Neuropathol. 2014, 33, 6-14. [CrossRef] [PubMed]

44. Yan, H.; Parsons, D.W.; Jin, G.; McLendon, R.; Rasheed, B.A.; Yuan, W.; Kos, I.; Batinic-Haberle, I.; Jones, S.; Riggins, G.J.; et al. IDH1 and IDH2 mutations in gliomas. N. Engl. J. Med. 2009, 360, 765-773. [CrossRef] [PubMed]

(C) 2020 by the authors. Licensee MDPI, Basel, Switzerland. This article is an open access article distributed under the terms and conditions of the Creative Commons Attribution (CC BY) license (http://creativecommons.org/licenses/by/4.0/). 